\title{
Comparing data Reported Using the National Health Management Information System and data Declared Validated on the PBF Declaration Forms in Funding Health Districts in Nasarawa State
}

\author{
Prince O. Ezekiel \\ Department of Planning, Research and Statistics (DPRS), Nasarawa State Primary Health \\ Care Development Agency, Nigeria
}

\begin{abstract}
The National Health Management Information System (NHMIS) was designed to provide timely and reliable health service delivery information. The efficiency and effectiveness of health service delivery is assessed by the availability of quality, complete and timely data. The NHMIS Policy review was initiated by a consortium of relevant stake holders led by the Department of Planning, Research and Statistics (DPRS) of the federal ministry of health (FMOH) and the National Primary Health Care Development Agency (NPHCDA). The Emphasis of the NHMIS Is to strengthen the Health Information System-HIS in the country and promote the use of quality information for evidence-based decision-making at the community, LGA, and national levels. In spite of substantial investments, the health sector in Nigeria has made slow progress in improving its health indices. Thus the Nigeria State Health Investment Project(NSHIP), through support from WHO, introduced the Performancebased financing -PBF currently rolled out in three states- Adamawa, Nasarawa, and the Ondo States to deliver a result-based approach to improve quantity and quality of health services especially in the area of maternal health. Health centers receive funds directly based on the number of essential services they delivered and the improved quality of care. This encouraged health centers to focus on delivering results, and the new funds enabled them to improve their services. This study compared data reported using the NHMIS and declared validated on the PBF declaration forms in funding health facilities in Nasarawa state for quarter 1 (Jan.- Mar.)2018 and quarter 2 (Apr. - June) 2018.
\end{abstract}

Keywords: Data Management, Data Validation, Financing, Health, Information, Systems, Monitoring, Performance.

\section{Introduction}

In 2006 the NHMIS policy was revised to recognize that the Health Information System (HIS) is an integral and major thrust of the health system in Nigeria [1]. The policy noted that the state of health of the Nigerian Population is assessed based on scanty and incomplete information. As such, the policy recommends strengthening the Health Information System (HIS) as a major tool for informed decision-making at all levels of governance $[2,3,4]$.
The NHMIS serves as the backbone for Monitoring results of Health activities implemented across the country based on the National Strategic Health Development Plan (NSHDP). The availability of accurate, timely, reliable, and relevant health data remains key in achieving informed public health actions $[5,6]$.

The fundamental role of the NHMIS involved data collection to showcase the country's health status, data quality enhancement and proper definition of each indicator therein, thorough data analysis at all 
levels of the health system and informed decision making by actors, timely feedback at all levels, enabling access of data at all levels to development partners and prompt epidemiological surveillance and timely intervention in the case of an epidemic [7, 8, 9]. The elements of an effective HMIS are its relevance, how it satisfies clearly defined and quantified public health goals, its performance, does it work with efficient methods and tools, and competent professionals? Its usefulness, how is it used by its targeted audience (decision-makers, health professionals, community stakeholders), and its consistency, are the various stakeholders and information sources well-coordinated? The setting of institutional mechanisms and incentives in order to introduce an evidence base decision-making process has been seen by many scholars as important and a major need. Thus, Performance-based financing at implementation had as one of its principles to strengthen the health system, not leaving out the NHMIS. In this light, the data reported in the project at the level of the health facility is supposed to be consistent with data reported in the NHMIS. This study sought to find out if this is the case on the field [10].

Consequently, to improve on the issue of scanty and incomplete information, the Federal Ministry of Health (FMOH) and the World Health Organization (WHO), together with development partners in 2012, introduced a Performance-Based Financing - PBF-System as an incentive to motivate health service providers to improve on the services they render to their various communities. This system has been piloted in other developing African countries like Cameron, Rwanda, etc., and is been recently implemented in Nigeria with Adamawa, Nasarawa, and Ondo as the pilot states [11].

The Nigeria State Health Investment Project (NSHIP) is currently implementing PBF in public and private facilities across the country, and Nasarawa state is among the pioneer states.
7 of the 13 LGAs in Nasarawa State are operating the PBF system i.e, Akwanga, Doma, Karu, Kokona, Nasarawa, Toto and Wamba and these will be involved in this study.

The NHMIS tool has been the backbone of collecting and transmitting vital health information at all levels in the Nigerian Health system. But there is a knowledge deficit in the use of this tool. The head of the facilities and the officer in charge seem not to have mastery of this tool. Data is first collected in the form of a source document which is summarized in the monthly summary forms that is further transmitted into the NHMIS tool eg DHIS-2, that is further reported to the state and national levels $[12,13,14]$. Unfortunately, enough, the data that is filled on this tool is most often not consistent with those reported in other projects. Most Chief of the Health unit do not ensure complete and timely filling of these forms talk more of taking time off to do adequate data quality checks before transmitting the reports to the state and national levels with the impression that reports are not fully exploited at the higher levels [15]. The NHMIS is disjointed by other reporting tools in vertical programmes, and Health Units head see it as a lot of work filling and completing the NHMIS. With the advent of PBF, State Medical Teams have evaluated on this tool to see the timeliness and completeness rate of health facilities effectively reporting using this tool. In performance-based financing, health facilities are supposed to report to the project using the declaration validation form for project indicators $[16,17]$.

Health facilities receive monetary incentives with autonomy to spent money in a way that improves the quality and quantity of the services they provide through the PBF system. It is hereby justifiable to ascertain if the data declared validated on the PBF projects has improved and if it is in tandem with data reported using the NHMIS tool.

Does the data that health facilities declare to the PBF Project using the declaration validation forms concordant with the data that is reported 
using the NHMIS tool? To Answer the research question, data reported using the NHMIS was compared with that declared using the PBF declaration/validation forms for some selected indicators in Nasarawa State, Nigeria, from January to March(Q1) and April- June(Q2) 2018 for consistency. This was specifically done by:

- Comparing the data validated by LGA supervisors to data declared in the NHMIS.

- Assessing reporting using both tools by category (ANC, Delivery, STD, etc.).

- Make possible recommendations for improvement.

The following operational terms have been used in this case study:

\section{Consistency}

These are health facilities/LGAs having concordant data for the same indicators in the NHMIS and PBF declaration validation forms with an error margin of $10 \%$.

\section{Under Reporting}

These are health facilities reporting less in the NHMIS compared to data in the PBF declaration validation forms in absolute terms for the same indicators with an error margin greater than $10 \%$.
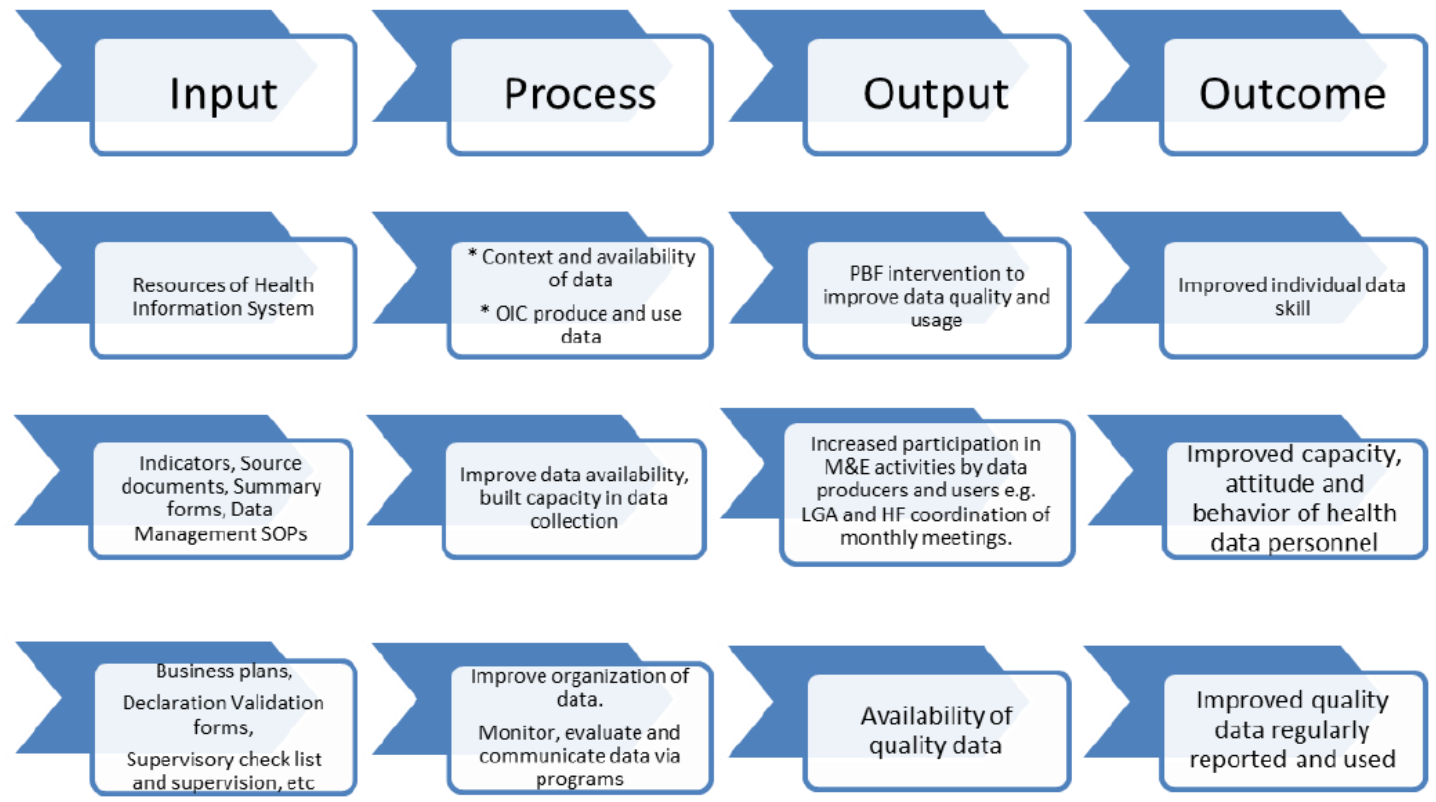

Figure 1. Logical Framework for Strengthening the Reporting and use of Health Data 
The logical model described in this study maps out how the intervention inputs and activities are expected to influence the outputs and eventual outcome of regular data reporting and use in program review, planning, advocacy, policy development, and other decision-making processes.

\section{Methodology}

The onset of this study required 6 indicators that were reported in the NMHIS that have the same definition in the PBF declaration validation forms were identified and selected. The NHMIS tool used is the DHIS-2 platform of Nasarawa state from the Nasarawa State Primary Health Care Development Agency (NAPHDA) covering the period January - June 2018. Data Reported in the NHMIS (DHIS-2) tool were entered in Spreadsheet and Exported to STATA data analysis software. Data declared in the PBF project for the aforementioned indicators was equally entered on this tool. This data was then analyzed on STATA by running frequency. P-values could not be used for this study because we had a random sample of 14 health facilities. Three cut off categories (underreporting, consistent, and over-reporting) were used to interpret the results.

\section{Results}

14 Health Facilities were involved in this study (2 Facilities from each of the 7 LGAs) in Nasarawa State, 13 (92.9\%) were public, while $1(7.1 \%)$ in karu LGA was a private clinic.

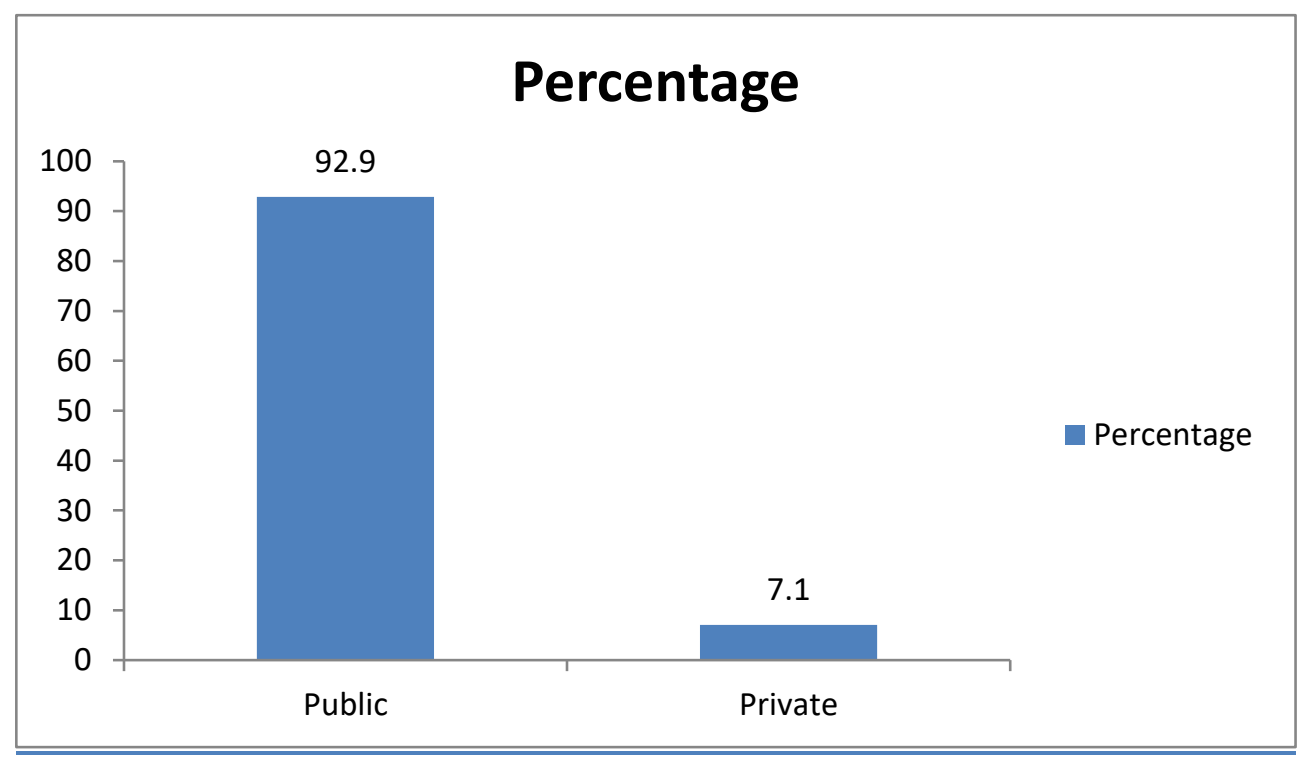

Figure 2. Type of Health Facility

Comparing Data Reported Using the NHMIS (DHIS-2) and the PBF Declaration/Validation forms

The table below depicts the reporting state in the NHMIS as compared with the PBF data, which was verified and validated. Reporting was categorized into 3 groups as regards the 6 indicators used for this study. The facilities were categorized to be either under-reporting, consistent in both the NHMIS and PBF or overreporting. The analysis below shows that the indicator(s) with the highest level of consistency in both tools was: Normal Delivery (35.71\%) and STD Treated with (35.72\%) as reported by the 14 facilities in this study. Amongst the 6 indicators that were used for this study, Only Delivery- Normal and STD Treated were able to score above $35 \%$ consistency, and none was able to score up to $50 \%$. In real-time, we expect a $100 \%$ consistency for these two indicators, although the level of consistency was set at $90 \%$ for this study. 
Table 1. Summarized State of Reporting in the NHMIS Compared to PBF Validated Data from January to June 2018 per Indicator

\begin{tabular}{|l|l|l|l|l|}
\hline Indicators & $\begin{array}{l}\text { \% Of HF Under } \\
\text { Reporting in } \\
\text { NHMIS }\end{array}$ & $\begin{array}{l}\text { \% Of HFs with } \\
\text { Consistent Data } \\
\text { in both tools }\end{array}$ & $\begin{array}{l}\text { \% Of HFs } \\
\text { Over reporting } \\
\text { in NHMIS }\end{array}$ & Total \\
\hline New Out Patience Consultation & 7.14 & 28.57 & 64.29 & 100 \\
\hline ANC 4TH Visit & 57.14 & 14.29 & 28.57 & 100 \\
\hline Delivery Normal & 14.29 & 35.71 & 50 & 100 \\
\hline Fully Immunize Children Under 1 & 14.29 & 7.14 & 78.57 & 100 \\
\hline STD Treated & 7.14 & 35.72 & 57.14 & 100 \\
\hline Post Natal Visit & 7.14 & 28.57 & 64.29 & 100 \\
\hline
\end{tabular}

Table 2. State of Reporting for New Outpatient Consultation by Status of Health Facility from January 2018 June 2018

\begin{tabular}{|l|l|l|l|}
\hline Indicator & \multirow{2}{*}{ State of Reporting } & \multicolumn{2}{|l|}{ Status of Health Facility } \\
\cline { 3 - 4 } & Stablic & Private \\
\cline { 2 - 4 } & \% Of HF Under Reporting & 14.29 & 7.14 \\
\cline { 2 - 4 } New Out Patience & \% Of HF with Consistent Data in Both tools & 28.57 & 0 \\
\cline { 2 - 4 } Consultation & \% Of HF Over Reporting & 50 & 0 \\
\cline { 2 - 4 } & Total & $\mathbf{1 0 0}$ & \multicolumn{2}{|l}{} \\
\hline
\end{tabular}

Table 3. State of Reporting for ANC 4TH Visit by Status of Health Facility from January 2018 - June 2018

\begin{tabular}{|l|l|l|l|}
\hline Indicator & \multirow{4}{*}{} & \multicolumn{2}{|l|}{ Status of Health Facility } \\
\cline { 3 - 4 } & State of Reporting & Public & Private \\
\cline { 2 - 4 } & $\%$ Of HF Under Reporting & 50 & 7.14 \\
\cline { 2 - 4 } & $\%$ Of Hf with Consistent Data in Both tools & 14.29 & 0 \\
\cline { 2 - 4 } ANC 4TH Visit & \% Of HF Over Reporting & 28.57 & 0 \\
\cline { 2 - 4 } & Total & $\mathbf{1 0 0}$ \\
\hline
\end{tabular}

Table 4. State of Reporting for Normal Delivery by Status of Health Facility from January 2018 - June 2018

\begin{tabular}{|l|l|l|l|}
\hline Indicator & \multirow{2}{*}{} & \multicolumn{2}{|l|}{ Status of Health Facility } \\
\cline { 3 - 4 } & State of Reporting & Public & Private \\
\cline { 2 - 4 } & $\%$ Of HF Under Reporting & 14.29 & 0 \\
\cline { 2 - 4 } & $\%$ Of Hf with Consistent Data in Both tools & 28.57 & 7.14 \\
\cline { 2 - 4 } Normal Delivery & To Of HF Over Reporting & 50 & 0 \\
\cline { 2 - 4 } & Total & $\mathbf{1 0 0}$ & \multicolumn{2}{|l}{} \\
\hline
\end{tabular}

Table 5. State of Reporting for Fully Immunized Children under 1 by Status of Health Facility from January 2018-June 2018

\begin{tabular}{|l|l|l|l|}
\hline Indicator & \multirow{4}{*}{ Status of Health Facility } \\
\hline \multirow{4}{*}{\begin{tabular}{l} 
Fully Immunize \\
\cline { 2 - 3 } Children Under 1 1
\end{tabular}} & Total of Reporting & 14.29 & 0 \\
\cline { 2 - 4 } & \% Of HF Under Reporting & 7.14 & 0 \\
\cline { 2 - 4 } & \% Of Hf with Consistent Data in Both tools & 71.43 & 7.14 \\
\cline { 2 - 4 } & \% Of HFer Reporting & $\mathbf{1 0 0}$ & \multicolumn{2}{|l}{} \\
\hline
\end{tabular}


Table 6. State of Reporting for STD Treated by Status of Health Facility from January 2018-June 2018

\begin{tabular}{|l|l|l|l|}
\hline Indicator & & \multicolumn{2}{|l|}{ Status of Health Facility } \\
\cline { 3 - 4 } & State of Reporting & Public & Private \\
\cline { 2 - 4 } & \% Of HF Under Reporting & 7.14 & 0 \\
\cline { 2 - 4 } & \% Of Hf with Consistent Data in Both tools & 28.57 & 7.14 \\
\cline { 2 - 4 } STD Treated & \% Of HF Over Reporting & 57.15 & 0 \\
\cline { 2 - 4 } & Total & $\mathbf{1 0 0}$ & \\
\hline
\end{tabular}

\section{Report by Categories}

of reporting by Status of health facilities per indicator.

The Graphs and figures below show the state

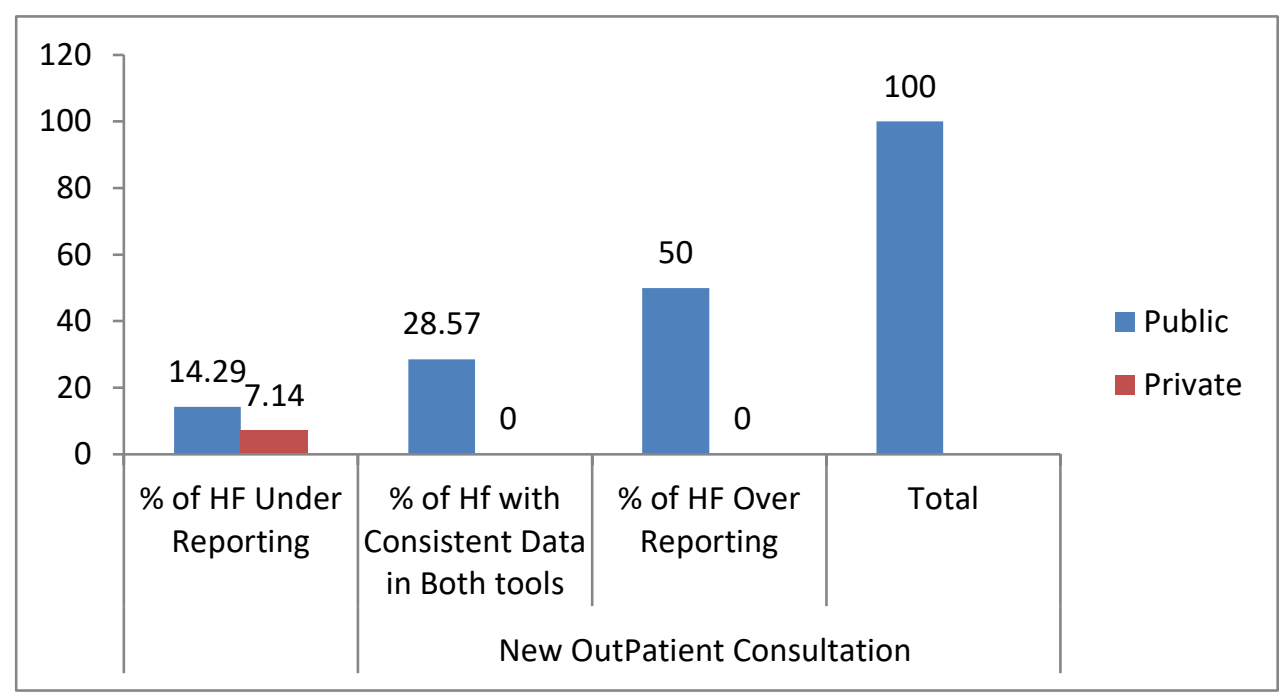

Figure 3. Reporting for New Outpatient Consultation by Status of Health Facility

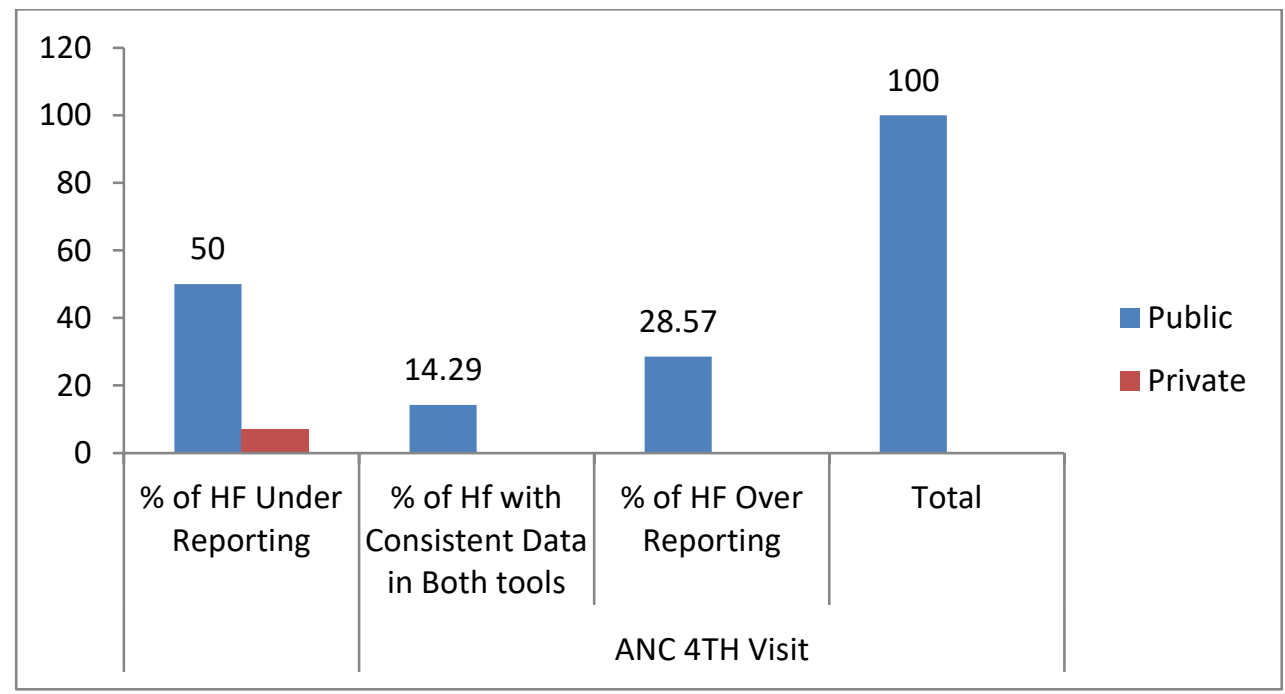

Figure 4. Reporting for ANC 4TH Visit by Status of Health Facility 


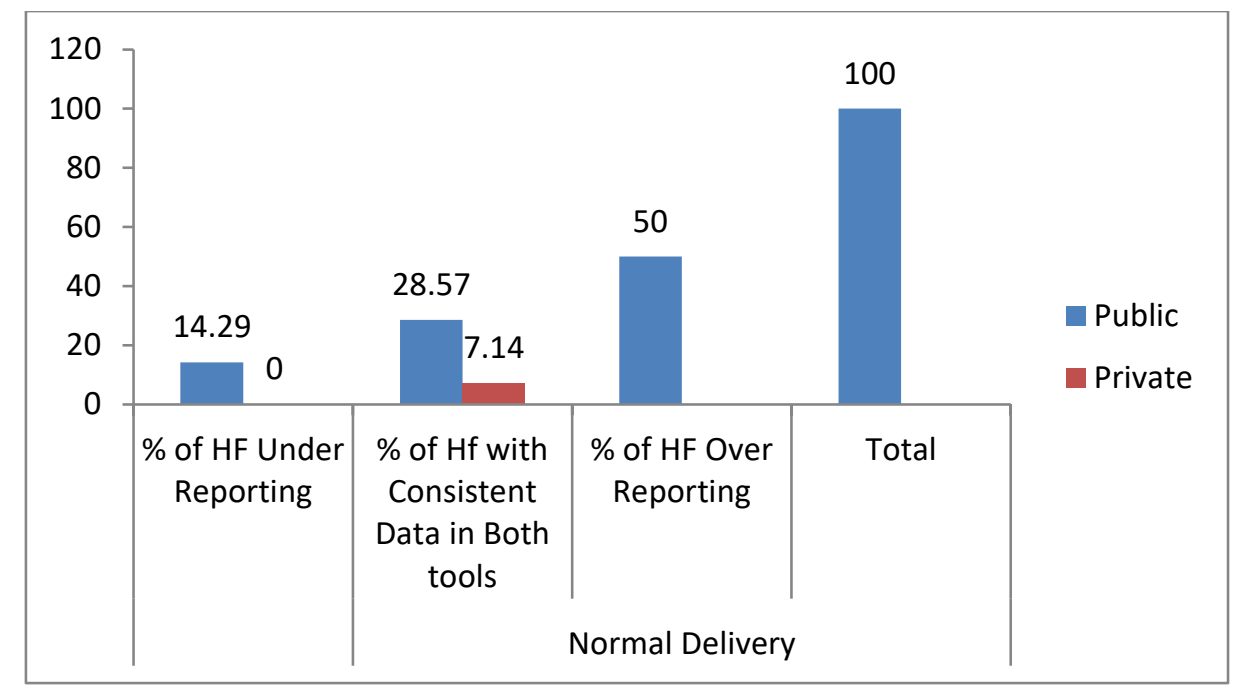

Figure 5. Reporting for Normal Delivery by Status of Health Facility

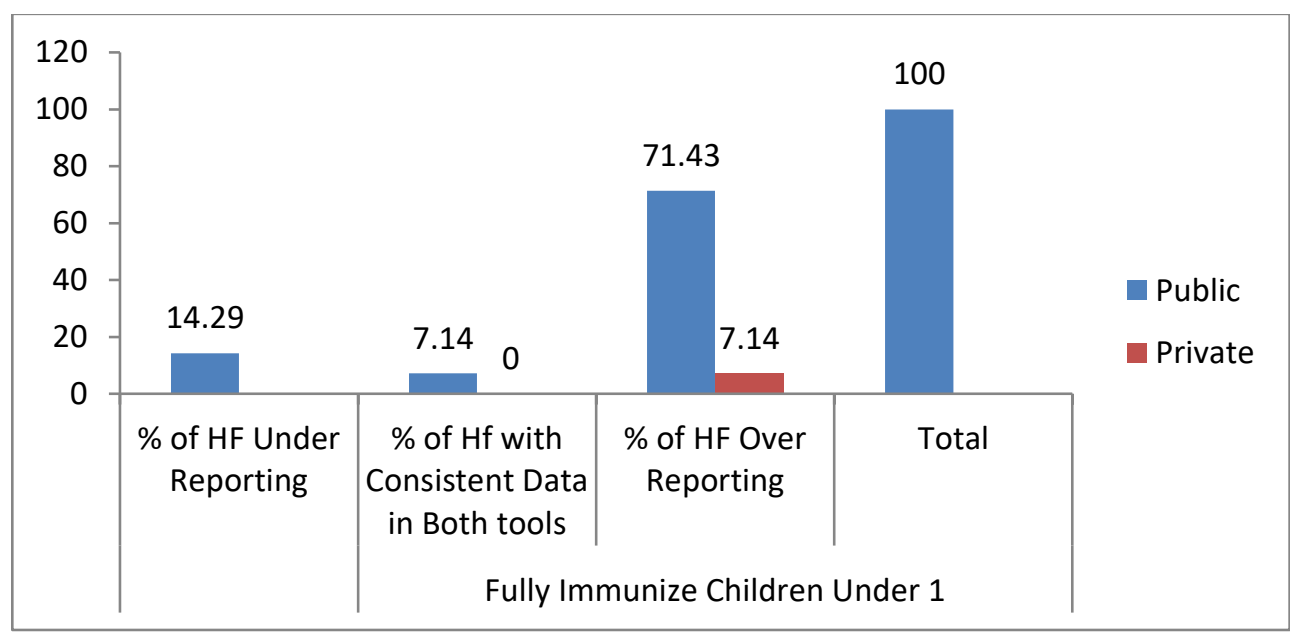

Figure 6. Reporting for Fully Immunized Children under 1 by Status of Health Facility

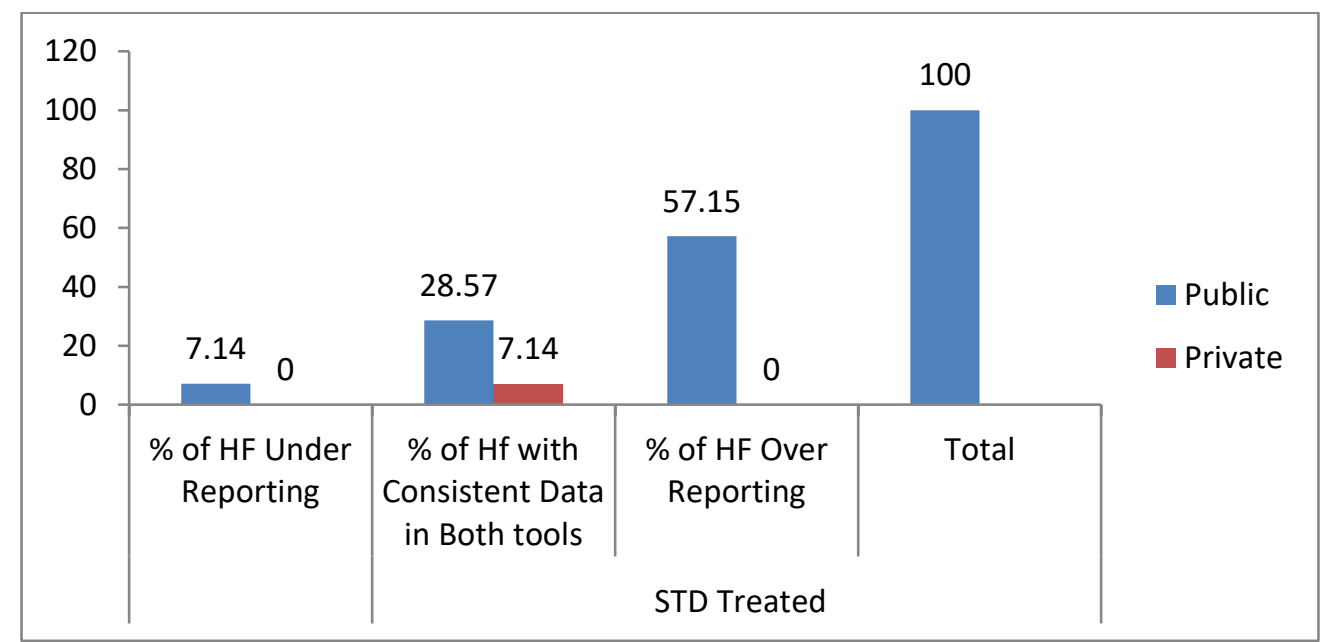

Figure 7. Reporting for STD Treated by Status of Health Facility 


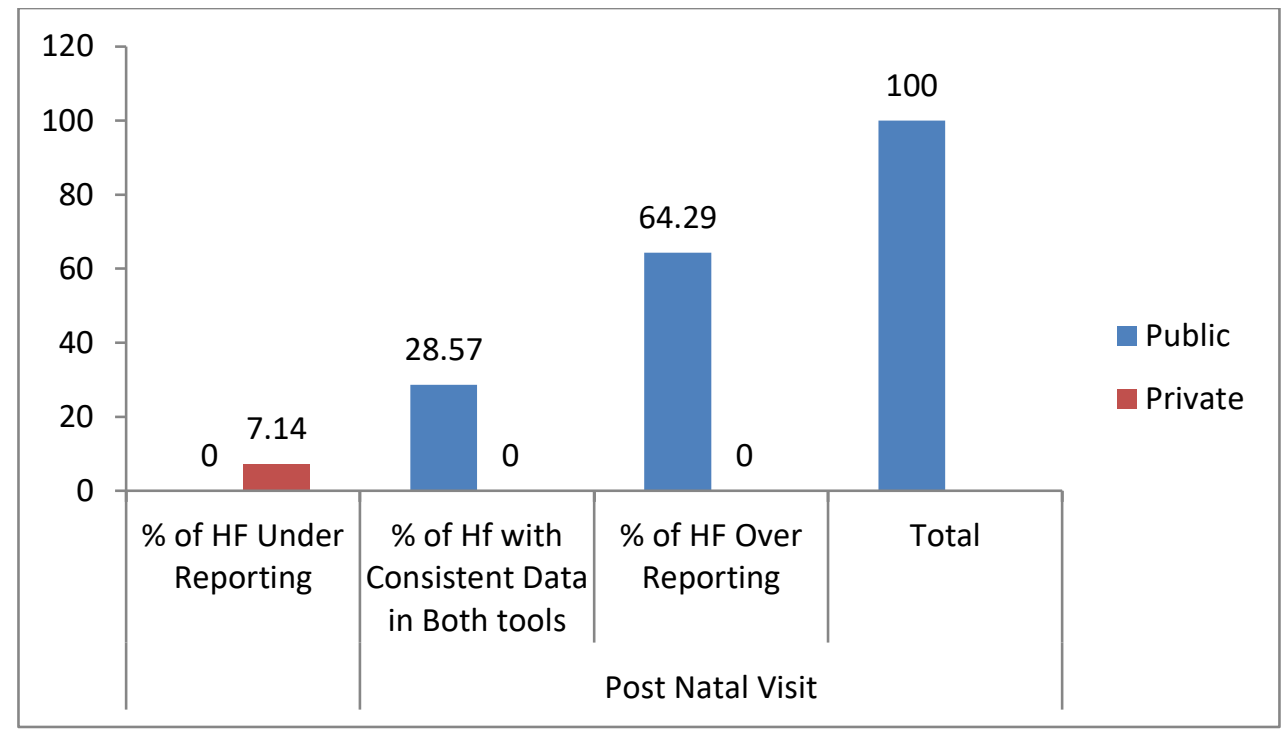

Figure 8. Reporting for Post Natal Visit by Status of Health Facility

\section{Discussions}

Reporting by category of health facility shows that even though only one Private Health Facility was used in this study, it was clear that public health facilities were seen to be more consistent in reporting using the NHMIS than private clinics. There are more public health facilities in the state compared to private clinics and confectionaries. Conversely, the private clinic was seen to be underreporting using the NHMIS than the public health facilities, while Public Health facilities were observed to be over-reporting using the NHMIS. This is in consonance with the outcome of a similar project in fundong district, Cameron, by Kum Ghabowen Iwinbong in 2014, as these studies show that the public health facilities have the tendency of proliferating figures in the NHMIS than when reporting using the PBF declaration validation form. It is obvious that facilities report more accurately on the $\mathrm{PBF}$ declaration/validation forms because they know that the data will be verified and validated but are complacent with the NHMIS since they are aware that this data is not thoroughly verified except for the routine Data Quality Assessment (DQA) that is usually not as indebt as that of the PBF data validation that has financial implications. Moreover, it could be interpreted that the private health facilities tend to conceal relevant information given the fact that they tend to underreport using the NHMIS.

\section{Conflict of Interest}

None

\section{Conclusion}

This study shows that out of 6 indicators, none attended 90\% consistency for the 14 health facilities in the study, which implies that the data reported in the NHMIS (DHIS-2) compared to the PBF declaration validation form is completely inconsistent. Private facilities were observed to be under-reporting in the NHMIS while public health facilities were over-reporting. In conclusion, the data reported in the NHMIS is not consistent with the data reported in the PBF declaration validation forms, indicating that data from NHMIS is not reliable.

\section{Recommendations}

The State Primary Health Care Development Agencies (SPHCDA) should regularly train and retrain the Officers in charge (OIC) of health facilities, $\mathrm{M} \& \mathrm{E}$, and other data focal persons on proper reporting in the NHMIS.

Health facilities should constantly compare data reported in the NHMIS with data reported in other parallel programs with similar indicators like PBF. 
The State Primary Health Care Development Agencies, in collaboration with the State Ministry of Health (SMOH) should endeavor to harmonize indicators that define same in the NHMIS and PBF portal to encourage consistency in reporting and data quality.

The State Primary Health Care Development Agencies, in collaboration with the State Ministry of Health (SMOH), should refresh health facility heads on generating data from the NHMIS, analyze and use the data for making decisions with respect to their business plan.

State and LGA Health teams should carry out their routine Integrated Supportive

\section{References}

[1] MEASURE Evaluation. 2017, Using DHIS 2 to Strengthen Health Systems. Chapel Hill, NC: MEASURE Evaluation, University of North Carolina;.5-6 Available: https://www.measureevaluation.org/resources/public ations/fs-17-212.

[2] Federal Ministry of Health. (2007). National Health Management Information System (NHMIS) Unit: Revised Policy and Strategic Plan of Action. Abuja, Nigeria: Federal Ministry of Health Nigeria. pp.1-3, https://ehealth4everyone.com/wpcontent/uploads/2015/09/Nig-Health-Info.pdf.

[3] Federal Ministry of Health, Nigeria, 2014, National Health Information System Strategic Plan (2014-2018). Federal Government of Nigeria., http://www.health.gov.ng/doc/National\%20HIS\%20Str ategic\% 20Plan.pdf.

[4] Health Data Collaborative, 2016, Nigeria to track health sector performance with coordinated partner support on health data, https://www.healthdatac ollaborative.org/news/article/nigeria-to-track-healthsector-performance-with-coordinated-partner-supporton-health-data-80/

[5] AbouZahr, C T., 2005, Health information systems: the foundations of public health. Bulletin of the World Health Organization, 83(8), 578-583, https://www.ncbi.nlm.nih.gov/pmc/articles/PMC262 $6318 /$.
Supervision (ISS) of NHMIS at the health facility level regularly for consistency with other programs.

\section{Acknowledgement}

I use this medium to thank Dr. Stephen Sasetu, Director, Planning Research and Statistics of the Nasarawa State Primary Health Care Development Agency, Nigeria, for initiating this research topic and supporting me to do this. I also thank the DPRS team of the Agency and my N-Power Colleagues, who supported me with the database for this analysis.

[6] Nyamtema A.S, 2010, Bridging the gaps in the Health Management Information System in the context of a changing health sector. BMC Medical Informatics \& Decision Making,10(1),36 https://bmcmedinformdecismak.biomedcentral.com/ articles/10.1186/1472-6947-10-36

[7] Olusesan A. M, Emmanuel C. M, Akin Oyemakinde, Kolawole A.O, Akinyemi Atobatele, Fadeke A. F, et all, 2018, The Nigerian Health Information Health Information System Policy Review of 2014: the need, content, expectations, and progress; Health information and library journal, 35, 285-297, https://onlinelibrary.wiley.com/doi/full/10.1111/hir. 12240.

[8] Jean S. N, Pierre Ongolo-Zogo, 2010, Reinforcing the Health Information System to Step up the Viabilization of Health District's Policy brief,1-11,

http://www.cdbph.org/documents/ongolo_en_Reinfo rcingHIS4DistrictViabilization_18jul10.pdf.

[9] Report A. African development fund, Nigeria Country Strategy,

2020-2024. https://www.gtai.de/resource/blob/549194/60a7991c cd54563a048748152fcecfb4/PRO20200908549188. pdf.

[10] Mutale W, Chintu N, Amoroso C, AwoonorWilliams K, Phillips J, Baynes C, et al. 2013, Improving health information systems for decision 
making across five sub-Saharan African countries: Implementation strategies from the African Health Initiative. BMC Health Services Research,13(2), https://bmchealthservres.biomedcentral.com/articles/ 10.1186/1472-6963-13-S2-S9.

[11] Nshimyiryo A, Kirk CM, Sauer SM, Ntawuyirusha E, Muhire A, Sayinzoga F, et al.,2020, Health management information system (HMIS) data verification: A case study in four districts in Rwanda, 15(7), https://journals.plos.org/plosone/article?id=10.1371/ journal.pone.0235823.

[12] Ouedraogo M, Kurji J, Abebe L, Labonté R, Morankar S, Bedru KH, et al., 2019, A quality assessment of Health Management Information System (HMIS) data maternal and child health in Jimma Zone, Ethiopia, 14(3), https://pubmed.ncbi.nlm.nih.gov/30856239/.

[13] O’Hagan R, Marx MA, Finnegan KE, Naphini P, Ng'ambi K, Laija K, et al., 2017, National Assessment of Data Quality and Associated Systems-Level Factors in Malawi. Global Health: Science and Practice.;5(3), https://pubmed.ncbi.nlm.nih.gov/28963173/.

[14] Venkateswaran M, Mørkrid K, Abu Khader K, Awwad T, Friberg IK, Ghanem B, et al., 2018, Comparing individual-level clinical data from antenatal records with routine health information systems indicators for antenatal care in the West Bank: A cross-sectional study,13, https://journals.plos.org/plosone/article?id=10.1371/ journal.pone.0207813.

[15] Kum Ghabowen Iwimbong, 2015, Comparing Data Reported using the National Health Management Information System and data Declared/Validated on the PBF Declaration forms in
Fundong Health District, South American Journal of Academic Research, 2(2), 1-9, https://www.texilajournal.com/thumbs/article/Acade mic\%20Research_Vol\%202_Issue\%202_Article_5. pdf.

[16] Kumar, M., Gotz, D., Nutley, T., \& Smith, J. B. (2017). Research gaps in routine health information system design barriers to data quality and use in low- and middle-income countries: A literature review. The International Journal of Health Planning and Management, 33(1), 1-9. https://doi.org/10.1002/hpm.

[17] Maduekwe, N. I., Banjo, O. O., \& Sangodapo, M. O. (2017). The Nigerian Civil registration and vital statistics system: Contexts, institutions, operation. Social Indicators Research, 134(2), 651674. https://doi.org/10.1007/s11205-016-1448-5.

[18] Upadhaya, N., Jordans, M. J. D., Abdulmalik, J., Ahuja, S., Alem, A., Hanlon, C., et all., Gureje, O. (2016). Information systems for mental health in six low- and middle-income countries: Cross country situation analysis. International Journal of Mental Health Systems, 10, 60. https://doi.org/10. 1186/s13033-016-0094-2.

[19] World Health Organization. (2008). Framework and standards for country health information systems. Retrieved 4 November 2015 from http://apps.who.int/iris/handle/10665/43872.

[20] Smith, Peter C, Karanikolos, Marina \& Cylus, Jonathan. (2018), European Observatory on Health Systems and Policies, Evolution of health system performance assessment: the roles of international comparisons and international institutions. Eurohealth, 24 (2), 15 - 18. World Health Organization. Regional Office for Europe. https://apps.who.int/iris/handle/10665/332564. 